\title{
Lifetime predictions of non-ionic and ionic biopolymers: kinetic studies by non-isothermal thermogravimetric analysis
}

\author{
Martina Maria Calvino ${ }^{1} \cdot$ Lorenzo Lisuzzo $^{1} \cdot$ Giuseppe Cavallaro $^{1,2} \oplus \cdot$ Giuseppe Lazzara $^{1,2} \cdot$ Stefana Milioto $^{1,2}$
}

Received: 15 May 2021 / Accepted: 18 June 2021 / Published online: 19 July 2021

(c) The Author(s) 2021

\begin{abstract}
In this paper, films based on sustainable polymers with variable charge have been investigated by non-isothermal thermogravimetry in order to predict their lifetime, which is a key parameter for their potential use in numerous technological and biomedical applications. Specifically, chitosan has been selected as positively charged biopolymer, while alginate has been chosen as negatively charged biopolymer. Among non-ionic polymers, methylcellulose has been investigated. Thermogravimetric measurements at variable heating rates $\left(5,10,15\right.$ and $\left.20{ }^{\circ} \mathrm{C} \mathrm{min}{ }^{-1}\right)$ have been performed for all the polymers to study their degradation kinetics by using isoconversional procedures combined with 'Master plot' analyses. Both integral (KAS and Starink methods) and differential (Friedman method) isoconversional procedures have shown that chitosan possesses the highest energetic barrier to decomposition. Based on the Master plot analysis, the decomposition of ionic polymers can be described by the R2 kinetic model (contracted cylindrical geometry), while the degradation of methylcellulose reflects the D2 mechanism (two-dimensional diffusion). The determination of both the decomposition mechanism and the kinetic parameters (activation energy and pre-exponential factor) has been used to determine the decay time functions of the several biopolymers. The obtained insights can be helpful for the development of durable films based on sustainable polymers with variable electrostatic characteristics.
\end{abstract}

Keywords Biopolymers $\cdot$ Methylcellulose $\cdot$ Chitosan $\cdot$ Alginate $\cdot$ Thermogravimetry $\cdot$ Lifetime

\section{Introduction}

In recent years, biopolymers have attracted a growing interest as sustainable alternatives for the fabrication of green materials promising for technological [1-5] and biomedical [6-13] applications. In this regard, polysaccharides have been largely used to replace the traditional packaging materials, which are based on petroleum-based plastics $[1,14,15]$. To this purpose, polysaccharides can be filled with inorganic nanoparticles (such as nanoclays with variable morphology, including halloysite nanotubes and kaolinite nanosheets) in order to obtain nanocomposite materials competitive with the traditional plastics in terms of mechanical resistance and thermal stability [15-17]. It is noteworthy that polysaccharides can be considered the most abundant group of natural macromolecules. Therefore, their use in the production of bioplastics presents both economic and environmental benefits [18]. As an example, a circular economy with the reduction of greenhouse gases can be achieved by using biodegradable sources such as natural polymers. In addition, the
Consorzio Interuniversitario Nazionale Per La Scienza E Tecnologia Dei Materiali, INSTM, Via G. Giusti, 9, 50121 Firenze, Italy

Highlights 1 . The lifetime predictions for biopolymeric films 2. Chitosan exhibits the largest energetic barrier to the decomposition compared to those of alginate and methylcellulose. be described by the R2 kinetic model (contracted cylindrical geometry)

4. The thermal decomposition of methylcellulose follows the

5. Chitosan possesses the largest half-life at $25^{\circ} \mathrm{C}$.

giuseppe.cavallaro@unipa.it

Dipartimento Di Fisica E Chimica, Università Degli Studi Di Palermo, Viale delle Scienze, pad. 17, 90128 Palermo, Italy

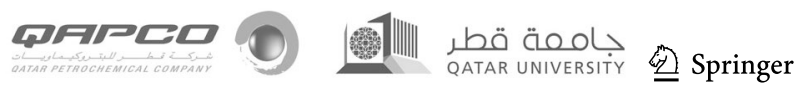


use of biopolymers decreases the municipal solid wastes, which are mostly composed of the traditional plastics. The biosynthesis of these macromolecules can occur in woods, algae and plants [14]. Additionally, they can be produced by fungi and bacteria [14]. The chemical and physico-chemical characteristics of polysaccharides are strictly dependent on their surface charge. As examples, cellulose is an uncharged biopolymer, while alginate and chitosan possess anionic and cationic groups, respectively [19].

Cellulose is a polymeric chain formed by glucose monomers strictly linked via $\beta$ - $(1 \rightarrow 4)$ glycosidic bonds. Due to its chemical composition, cellulose is insoluble in aqueous media limiting its use for numerous purposes [20,21]. The chemical modification of cellulose drives to the synthesis of water-soluble biopolymers that can be employed for different types of applications, including drug delivery [22, 23] and materials sciences [19, 21, 24]. Within this, cellulose ethers (such as methylcellulose, hydroxypropylcellulose and carboxymethylcellulose) were employed in the fabrication of functional biomaterials, which include sustainable films for packaging [19], hydrogels as carriers for active molecules [25] and surface protectives of artworks [26].

Alginate was widely employed in biomedical applications, such as in the development of injectable biomaterials [27], nanofibers for wound healing [28] and scaffolds for tissue engineering [29]. The combination of alginate with methylcellulose allowed for the fabrication of antimicrobial films, which were obtained through the tape-casting method [30].

Chitosan represents an emerging biopolymer due to its antimicrobial and hydrophobic properties. Recent literature proved that chitosan prevents the proliferation of pathogens promoting the plant growth [31]. As evidenced in a recent review [32], chitosan combined with oppositely charged polyanions (polyelectrolytes, surfactants) can generate different types of composites (coacervate, soluble complex, thin films, hydrogel) with specific functionalities. In this regard, chitosan/hyaluronan multilayers can be considered suitable as bone scaffolds because of their efficient coating capacity of substrate materials [33]. Layered composite tablets for sodium diclofenac were fabricated by exploiting the electrostatic attractions between chitosan and alginate [34]. The sequential casting procedure was employed for the preparation of flame retardant films based on chitosan matrix filled with halloysite clay nanotubes [35].

As expected, the lifetime of the biopolymers represents a crucial parameter in the fabrication of biocompatible packaging materials. Non-isothermal thermogravimetry represents an accelerated tool for the lifetime prediction of organic molecules, including polymers $[36,37]$ and drugs $[38,39]$. Furthermore, isothermal thermogravimetric approaches can be employed to determine the kinetics of degradation for several polymeric materials [36] as well as for biomasses
$[40,41]$. To this purpose, both integral and differential isoconversional methods revealed adequate to study the kinetics of the thermal decomposition of the macromolecules. The further investigation of the thermogravimetric data with the Master plot analysis drives to the determination of the full kinetic parameters and, consequently, to the simulation of the decay time functions at variable temperatures. Accordingly, the lifetimes of the investigated materials can be easily predicted. Within this, literature reports that non-isothermal thermogravimetry was successful in the lifetime estimation of polar (such as chitosan) [42] and apolar polymers, including polyethylene [43] and polypropylene [44] particles. It should be noted that the thermal characterization of microparticles based on thermoplastic polymers is crucial for their use in advanced technological applications [45]. In this work, non-isothermal thermogravimetry was employed to predict the lifetimes of sustainable films based on both ionic (alginate and chitosan) and non-ionic (methylcellulose) biopolymers. The obtained results can be helpful for the development of packaging materials based on bioplastics.

\section{Experimental}

\subsection{Materials}

Chitosan (molecular weight $=50-190 \mathrm{~kg} \mathrm{~mol}^{-1}$; deacetylation degree $=75-85 \%$ ), methylcellulose (average molecular weight $=14 \mathrm{~kg} \mathrm{~mol}^{-1}$, degree of methyl substitution $=27.5-31.5 \%$ ), sodium alginate (molecular weight $=70-100 \mathrm{~kg} \mathrm{~mol}^{-1}$ ) and glacial acetic acid are Sigma-Aldrich products.

\subsection{Preparation of biopolymer-based films}

Biopolymer-based films were prepared by using the aqueous casting method reported by Bertolino et al. [19]. To this purpose, each biopolymer was homogeneously dispersed in water by magnetically stirring for $2 \mathrm{~h}$ at $25^{\circ} \mathrm{C}$. The concentration of the biopolymer dispersions was fixed at $2 \mathrm{wt} \%$. It should be noted that chitosan was dissolved in aqueous solvent at $\mathrm{pH}=4$, which was reached by adding $0.1 \mathrm{~mol} \mathrm{dm}^{-3}$ of glacial acetic acid dropwise to water. Afterwards, the biopolymer dispersions were poured into glass Petri dishes (diameter $=9 \mathrm{~cm}$ ) at $40{ }^{\circ} \mathrm{C}$ until the complete water evaporation. After the removal from the dishes, the films were stored in a desiccator at $25^{\circ} \mathrm{C}$.

\subsection{Non-isothermal thermogravimetric analysis}

Thermogravimetric (TG) analyses were carried out through a Q5000 IR apparatus (TA Instruments) under nitrogen atmosphere. In this regard, the experiments were conducted 
using nitrogen flows of 25 and $10 \mathrm{~cm}^{3} \mathrm{~min}^{-1}$ for the sample and the balance, respectively. The mass of each sample was $5.0 \pm 0.5 \mathrm{mg}$. The films were grounded before the TG analyses, which were carried out using Platinum-HT sample pans $(100 \mu \mathrm{L})$. The TG measurements were performed in the range between 25 and $600{ }^{\circ} \mathrm{C}$, while the heating ramp was systematically varied in order to investigate the kinetics of the biopolymer degradation by non-isothermal thermogravimetric methods. Specifically, we selected heating rates $(\beta)$ of $2,5,10,15$ and $20{ }^{\circ} \mathrm{C} \mathrm{min}{ }^{-1}$. Prior to the determination of the kinetic parameters, we compared the thermal stability of the different biopolymer films by the analyses of the TG curves at $5{ }^{\circ} \mathrm{C} \min ^{-1}$. Within this, we determined the onset temperature $\left(\mathrm{T}_{\text {ons }}\right)$ as well as the decomposition temperature $\left(\mathrm{T}_{\mathrm{d}}\right)$ taken at the peak of the differential thermogravimetric (DTG) curves. Moreover, we calculated the mass change from 25 to $150{ }^{\circ} \mathrm{C}\left(\mathrm{ML}_{150}\right)$ to estimate the moisture content of the biopolymer films. As concerns the kinetic investigation, the TG curves at variable heating rates were analysed by KAS and Friedman methods in order to determine the activation energies $\left(\mathrm{E}_{\alpha}\right)$ of the biopolymer decomposition on dependence of the conversion degree $(\alpha)$. In addition, the Master plot analysis was used for the treatment of the TG data allowing us to estimate the pre-exponential factor of the decomposition process and, consequently, the lifetime of the biodegradable films.

\subsubsection{Isoconversional methods and Master plot analysis}

KAS method is an integral isoconversional procedure based on the following equation [46]:

$\ln \left(\frac{\beta_{i}}{T_{\alpha, i}^{2}}\right)=\operatorname{Cos} t-\frac{E_{\alpha}}{R T_{\alpha}}$

where $T_{\alpha, i}$ represents the temperature with a specified conversion degree $(\alpha)$ under a selected heating rate $(\beta)$. According to Eq. 1, the slope of $\ln \left(\beta / T^{2}\right)$ vs $1 / T$ plots allows us to calculate the activation energy at variable conversion degree $(E \alpha)$.

Another integral isoconversional procedure is the Starink approach [47]. It allows us to obtain a more accurate estimate of $E_{\alpha}$ and the method is described as

$\ln \left(\frac{\beta_{i}}{T_{\alpha, i}^{1.92}}\right)=$ Cost $-1.0008\left(\frac{E_{\alpha}}{R T_{\alpha}}\right)$

Thus, $E_{\alpha}$ can be calculated from the slope of plots of $\ln (\beta /$ $T^{2}$ ) versus $1 / T$.

The Friedman approach is a differential isoconversional method, which correlates $E_{\alpha}$ to the first derivative of $\alpha$ with respect to temperature $(d \alpha / d T)$. The Friedman method can be expressed as $\ln \left(\beta \frac{d \alpha}{d T}\right)_{\alpha, i}=\ln \left[f(\alpha) A_{\alpha}\right]-\frac{E_{\alpha}}{R T_{\alpha, i}}$

being $f(\alpha)$ a function of the extent of conversion, while $A$ and $R$ are the pre-exponential factor and the gas constant, respectively. Based on Eq. 3, $E_{\alpha}$ can be estimated by the slope of the $\ln (\beta d \alpha / d T)$ vs $1 / T$ linear trends.

The Master plot analysis was conducted by the determination of the $\mathrm{y}(\alpha)$ curve as

$y(\alpha)=\left(\frac{d \alpha}{d t}\right)_{\alpha} \exp \left(\frac{E_{0}}{R T_{\alpha}}\right)$

where $\mathrm{E}_{0}$ represents the average activation energy estimated from the isoconversional procedures.

\section{Results and discussion}

\subsection{Thermal behaviour of the biopolymer-based films}

The thermal stability of the biopolymer films was explored by thermogravimetry, which is an established technique for the thermal characterization of macromolecules [48-53]. A preliminary investigation on the thermal characteristics of the films was carried out by the analysis of the TG curves determined at $\beta=5{ }^{\circ} \mathrm{C} \mathrm{min}-1$ (Fig. 1).

As a general consideration, we observed a mass loss from 25 to $150^{\circ} \mathrm{C}$ due to expulsion of the water molecules physically adsorbed on the biopolymer films. On this basis, the $\mathrm{ML}_{150}$ values (Table 1) reflect the moisture content of the materials. We detected that alginate and chitosan possess similar affinities towards water, while the $\mathrm{ML}_{150}$ value of methylcellulose is significantly lower compared to the ionic biopolymers.

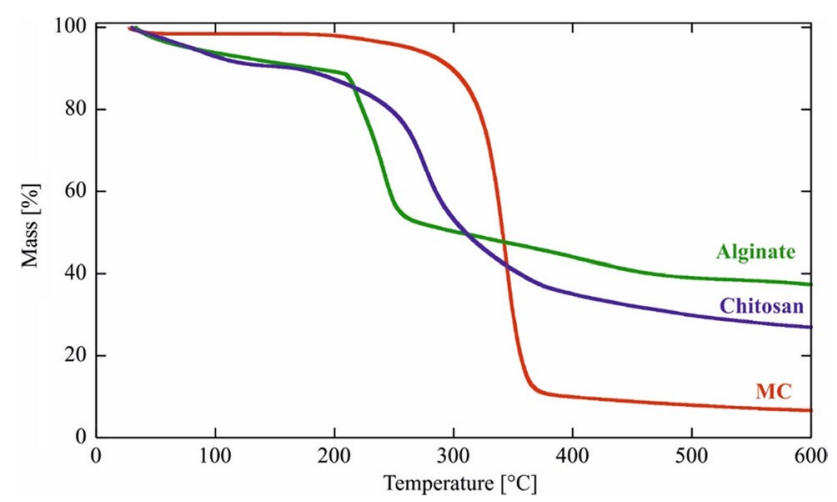

Fig. 1 Thermogravimetric curves of biopolymer films obtained at $\beta=5{ }^{\circ} \mathrm{C} \min ^{-1}$ 
Table 1 Thermogravimetric parameters obtained at $\beta=5{ }^{\circ} \mathrm{C} \mathrm{min}-1$

\begin{tabular}{llll}
\hline Biopolymer & $\mathrm{ML}_{150}(\mathrm{wt} \%)$ & $\mathrm{T}_{\text {ons }}\left({ }^{\circ} \mathrm{C}\right)$ & $\mathrm{T}_{\mathrm{d}}\left({ }^{\circ} \mathrm{C}\right)$ \\
\hline Methylcellulose & $1.42 \pm 0.02$ & $314 \pm 4$ & $344 \pm 4$ \\
Chitosan & $9.37 \pm 0.09$ & $246 \pm 3$ & $275 \pm 3$ \\
Alginate & $8.42 \pm 0.09$ & $218 \pm 3$ & $241 \pm 3$ \\
\hline
\end{tabular}

As shown in Fig. 1, the films evidenced a mass loss in the range $200-420{ }^{\circ} \mathrm{C}$ due to the thermal decomposition of the biopolymers. Specifically, this degradation stage can be attributed to the fracture of glycosidic bonds, dehydration, decarboxylation and decarbonylation for alginate [54], while the deacetylation and the cleavage of glycosidic linkages contribute to the decomposition of chitosan [42]. It should be noted that the alginate exhibited a small mass loss at ca. $500{ }^{\circ} \mathrm{C}$ because of the thermal degradation of fragments formed in the previous degradation stage [54]. Similarly, chitosan evidenced a degradation step in the range $450-600{ }^{\circ} \mathrm{C}$ that can be related to the thermal destruction of pyranose ring as well as to the decomposition of the residual carbon [42]. Oppositely, the MC degradation occurred in one single step due to the cleavage of glycosidic bonds as reported in literature [55]. We explored the thermal resistance to the degradation by considering the corresponding onset temperatures $\left(\mathrm{T}_{\mathrm{ons}}\right)$, which are presented in Table 1. Moreover, we determined the decomposition temperatures $\left(\mathrm{T}_{\mathrm{d}}\right)$ from the peaks of the DTG curves (Fig. 2).

Both $\mathrm{T}_{\text {ons }}$ and $\mathrm{T}_{\mathrm{d}}$ data highlighted that methylcellulose possesses the highest thermal stability, while alginate is the biopolymer with the lowest resistance to the thermal degradation. In particular, we observed that the decomposition temperature of methylcellulose is larger of ca. 70 and $100{ }^{\circ} \mathrm{C}$ compared to those of chitosan and alginate, respectively.

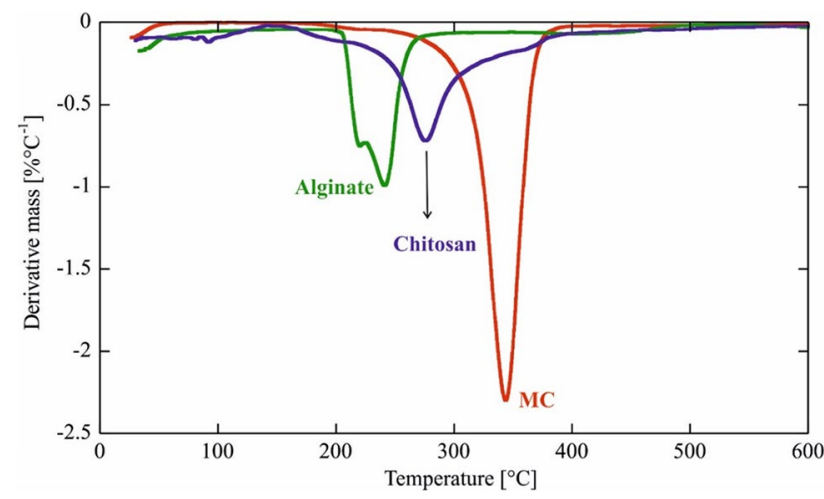

Fig. 2 Differential thermogravimetric curves of biopolymer films obtained at $\beta=5^{\circ} \mathrm{C} \min ^{-1}$

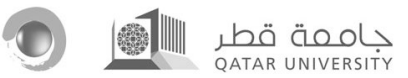

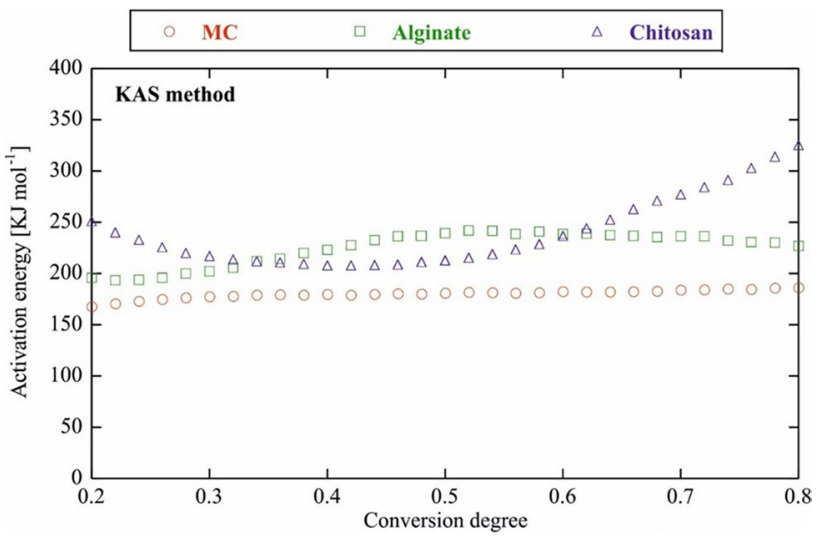

Fig. 3 Dependence of the activation energy on the conversion degree determined by KAS method

\subsection{Kinetics of the biopolymer degradation}

The kinetics of the biopolymer degradation was studied through non-isothermal thermogravimetry using isoconversional procedures (KAS, Starink and Friedman methods) combined with Master plot analysis. Similar approaches were used for the kinetic investigations of macromolecules $[39,56,57]$ and organic/inorganic composite materials [35, 49].

Figure 3 shows the dependences of the activation energy of the biopolymer degradation on the conversion degree determined by using the KAS approach.

According to literature [46], we can state that the activation energy is constant within the whole conversion degree range for all biopolymers being that the variations between the maximum and minimum values of $\mathrm{E}_{\alpha}$ are lower than $20-30 \%$ of the average activation energy. Similar observations were detected for $E_{\alpha}$ vs $\alpha$ trends determined by Starink method (Fig. 4).

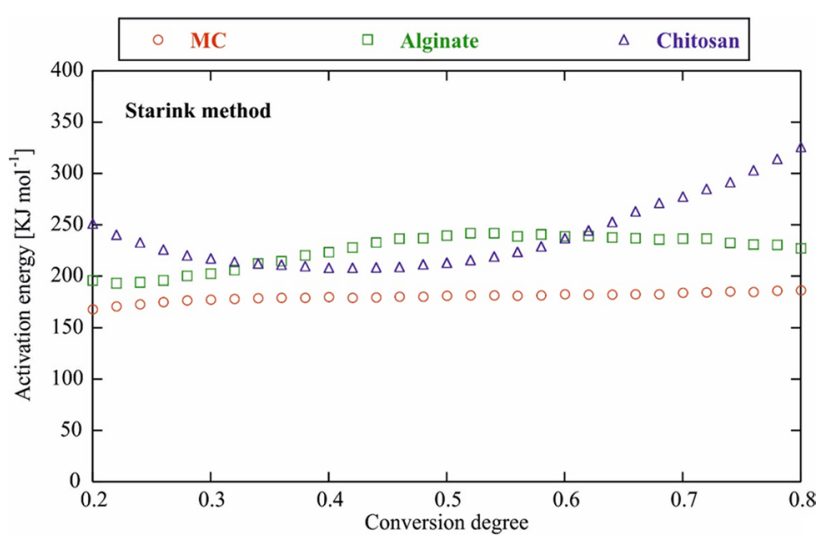

Fig. 4 Dependence of the activation energy on the conversion degree determined by Starink method 


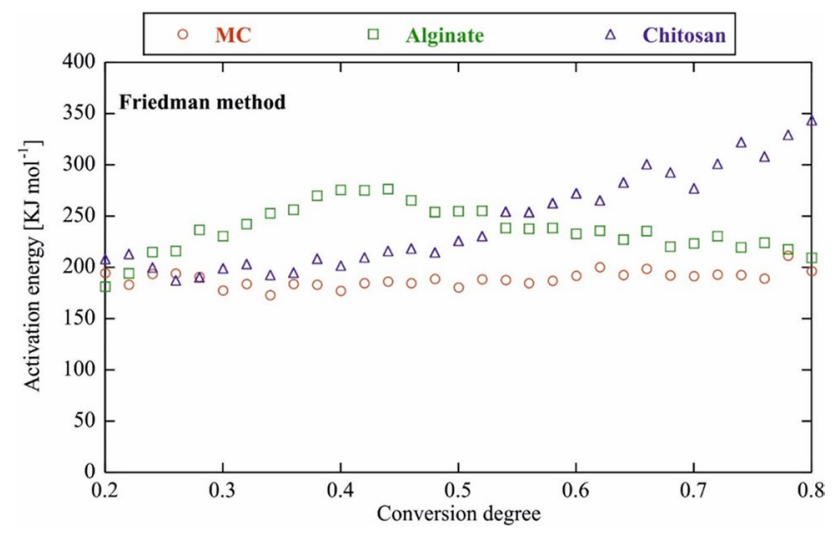

Fig. 5 Dependence of the activation energy on the conversion degree determined by Friedman method

As shown in Fig. 5, the analyses by Friedman method provided $E_{\alpha}$ vs $\alpha$ functions with a greater level of noise with respect to those obtained by KAS method (Fig. 3). Similar results were detected for the kinetic studies of cellulose degradation in historical woods [58].

We calculated the average activation energies (Table 2) for the degradation processes of the biopolymers using the $E_{\alpha}$ values obtained by both isoconversional procedures. We observed that the average activation energies obtained by KAS method are comparable to those calculated by using both Starink and Friedman approaches. In addition, we detected that KAS and Starink methods provided more accurate results as evidenced by the smaller errors on the average activation energies.

As a general result, we observed that that the degradation of methylcellulose presents the lowest activation energy compared to those related to the thermal decomposition of the ionic biopolymers. However, it should be noted that the activation energy values depend on the specific mechanism of the polymer decomposition. On this basis, the direct comparison of the activation energy values is valid if the degradation processes of all biopolymers can be described by the same kinetic model. According to this consideration, the Master plot analysis was conducted on the TG data in order to obtain the decomposition mechanism and, consequently, the full kinetics parameters, which allowed us to predict the lifetime of the biopolymers. To this purpose, we determined the $\mathrm{y}(\alpha)$ Master plots by Eq. 4 . It should be noted the Master plot analyses were carried out

Table 2 Average activation energies for the biopolymer degradation calculated by KAS, Friedman and Starink methods

\begin{tabular}{lclc}
\hline Biopolymer & $\begin{array}{l}\mathrm{E}_{0}(\text { from KAS }) \\
\left(\mathrm{KJ} \mathrm{mol}^{-1}\right)\end{array}$ & $\begin{array}{l}\mathrm{E}_{0} \text { (from Fried- } \\
\mathrm{man}) \\
\left(\mathrm{KJ} \mathrm{mol}^{-1}\right)\end{array}$ & $\begin{array}{l}\mathrm{E}_{0} \text { (from } \\
\text { Starink) } \\
\left(\mathrm{KJ} \mathrm{mol}^{-1}\right)\end{array}$ \\
\hline Methylcellulose & $180 \pm 4$ & $190 \pm 8$ & $181 \pm 4$ \\
Alginate & $225 \pm 16$ & $235 \pm 23$ & $226 \pm 16$ \\
Chitosan & $240 \pm 36$ & $268 \pm 47$ & $241 \pm 37$ \\
\hline
\end{tabular}

using only the $\mathrm{E}_{0}$ values from KAS method because of the higher accuracy with respect to those obtained by Friedman approach. The obtained $\mathrm{y}(\alpha)$ vs $\alpha$ plots was interpreted on the basis of the ICTAC recommendations [46] highlighting that the degradation of ionic biopolymers (chitosan and alginate) can be described by the R2 kinetic model (contracted cylindrical geometry), while the decomposition of methylcellulose can be ascribed to the $\mathrm{D} 2$ mechanism (two-dimensional diffusion). It should be noted that both R2 and D2 are reaction models of the decelerating type [46].

According to the $\mathrm{R} 2$ mechanism, the pre-exponential factors for the degradation of ionic biopolymers were determined by fitting the $\mathrm{y}(\alpha)$ data with the following equation

$y(\alpha)=A 2(1-\alpha)^{\frac{1}{2}}$

We determined A values of $1.26 \cdot 10^{21} \mathrm{~s}$ and $4.58 \cdot 10^{20} \mathrm{~s}$ for alginate and chitosan, respectively.

On the other hand, the pre-exponential factor for the degradation of methylcellulose $\left(\mathrm{A}=3.32 \cdot 10^{13} \mathrm{~s}\right)$ was estimated using the following expression (valid for the D2 kinetic model):

$y(\alpha)=A\left[-\ln ((1-\alpha)]^{-1}\right.$

The determination of the degradation mechanisms as well as the kinetic parameters (activation energies and preexponential factors) can be exploited to predict the lifetimes of the biopolymer films at variable temperatures.

\subsection{Lifetime prediction of the biopolymer-based films}

The time $\left(\mathrm{t}_{\alpha}\right)$ needed to reach a certain conversion degree at a fixed temperature $\left(\mathrm{T}_{0}\right)$ is related to the kinetic parameters of the biopolymer degradation by the following equation:

$t_{\alpha}=\frac{g(\alpha)}{A \exp \left(-\frac{E}{R T_{0}}\right)}$

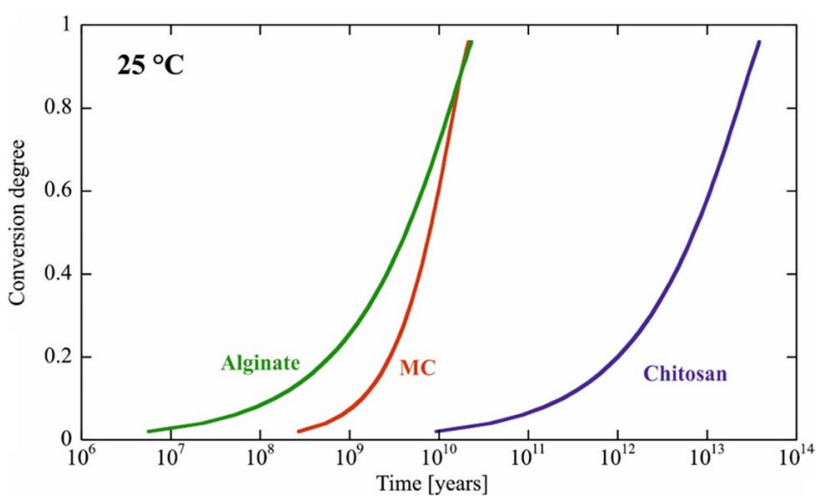

Fig. 6 Simulations of the conversion degree vs time trends at $25{ }^{\circ} \mathrm{C}$. The curves represent the lifetime predictions of the biopolymers

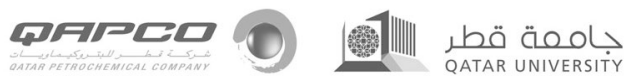




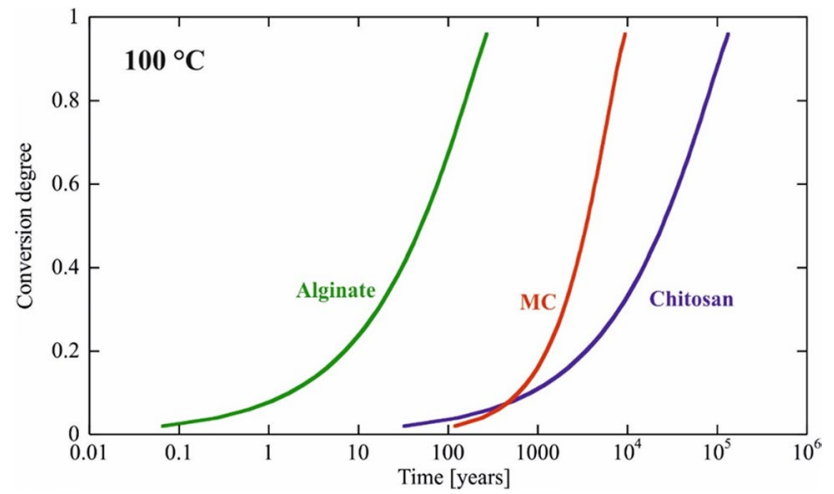

Fig. 7 Simulations of the conversion degree vs time trends at $100{ }^{\circ} \mathrm{C}$. The curves represent the lifetime predictions of the biopolymers

where $\mathrm{g}(\alpha)$ is the integral form of the reaction model that depends on the specific mechanism. As concerns the kinetic models employed for the investigated biopolymers, $\mathrm{g}(\alpha)=1-(1-\alpha)^{1 / 2}$ and $\mathrm{g}(\alpha)=[(1-\alpha) \cdot \ln (1-\alpha)+\alpha]$ represent the functions for R2 and D2 mechanisms, respectively.

According to Eq. 7, we determined the $\mathrm{t}_{\alpha}$ vs $\alpha$ curves at $\mathrm{T}_{0}=25$ (Fig. 6), 100 (Fig. 7) and $300{ }^{\circ} \mathrm{C}$ (Fig. 8). These trends represent the simulations of the biopolymer decomposition over time under isothermal conditions driving to the prediction of the lifetimes for chitosan, alginate and methylcellulose.

Based on the simulated curves, we determined the half-lives $\left(\mathrm{t}_{1 / 2}\right)$ of the biopolymers (Table 3 ). Namely, we calculated the times at which the films lose $50 \%$ of their initial weights. As reported in literature [59], $\mathrm{t}_{1 / 2}$ values are generally used to describe the lifetimes of polymeric materials.

Based on the data in Table 3, we can state that chitosan is the biopolymer with the highest stability at 25 and $100{ }^{\circ} \mathrm{C}$, while $\mathrm{MC}$ shows the largest half-life at $300{ }^{\circ} \mathrm{C}$. As a general result, alginate exhibited the lowest resistance to

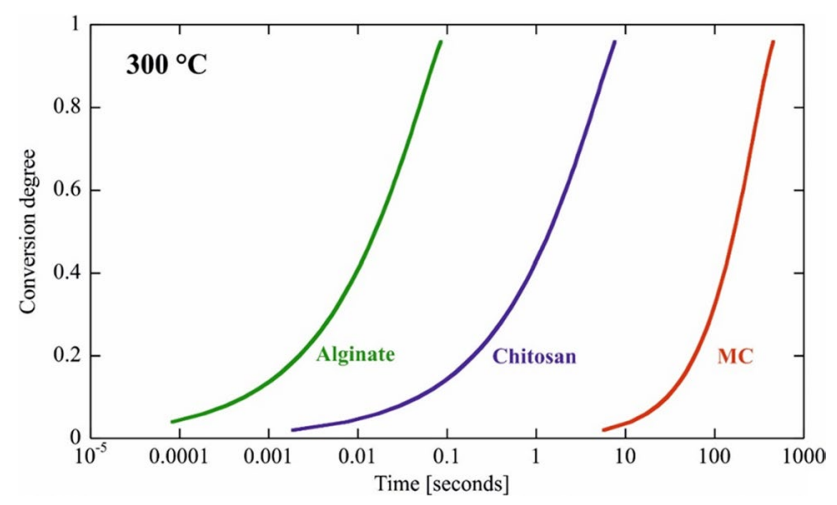

Fig. 8 Simulations of the conversion degree vs time trends at $300^{\circ} \mathrm{C}$. The curves represent the lifetime predictions of the biopolymers
Table 3 Half-lives of the biopolymers at $\mathrm{T}=25,100$ and $300{ }^{\circ} \mathrm{C}$

\begin{tabular}{llll}
\hline Biopolymer & $\begin{array}{l}\text { Half-life at } 25^{\circ} \mathrm{C} \\
\text { (years) }\end{array}$ & $\begin{array}{l}\text { Half-life at } \\
100{ }^{\circ} \mathrm{C} \\
\text { (years) }\end{array}$ & $\begin{array}{l}\text { Half-life } \\
\text { at } 300{ }^{\circ} \mathrm{C} \\
(\mathrm{s})\end{array}$ \\
\hline Methylcellulose & $7.86 \cdot 10^{9}$ & 3456 & 166 \\
Alginate & $4.27 \cdot 10^{9}$ & 49.9 & 0.02 \\
Chitosan & $7.11 \cdot 10^{12}$ & 24,475 & 1.4 \\
\hline
\end{tabular}

the degradation. It is important to note that TG measurements were conducted using Nitrogen flows. Therefore, the $t_{1 / 2}$ values reflect the lifetimes of the films under inert atmosphere.

\section{Conclusions}

The kinetic characteristics of the thermal decomposition of biopolymer films were estimated by non-isothermal thermogravimetry. In particular, isoconversional procedures (KAS, Starink and Friedman methods) combined with the Master plot analysis allowed us to determine the full kinetic path (activation energy, pre-exponential factor and reaction mechanism) useful to predict the lifetime of all the biopolymers. In this study, we investigated films based on differently charged biopolymers, including alginate (anionic), chitosan (cationic) and methylcellulose (non-ionic). All isoconversional procedures evidenced that the chitosan degradation presents the largest activation energy. In particular, the average activation energies determined from KAS method were 240,225 and $180 \mathrm{~kJ} \mathrm{~mol}^{-1}$ for the decomposition processes of chitosan, alginate and methylcellulose, respectively. The Master plot analysis showed that the decomposition of both chitosan and alginate can be described by the R2 kinetic model (contracted cylindrical geometry), while the degradation of methylcellulose follows the D2 mechanism (twodimensional diffusion). Based on the kinetic parameters, we determined the simulations of the decay time functions for the biopolymer films at 25,100 and $300{ }^{\circ} \mathrm{C}$. The half-lives obtained from the simulated functions highlighted that chitosan possesses the strongest resistance to the decomposition at 25 and $100{ }^{\circ} \mathrm{C}$. On the other hand, MC exhibited the largest half-life at $300{ }^{\circ} \mathrm{C}$. In conclusion, this work evidences that non-isothermal thermogravimetry represents an effective tool to investigate the lifetime of biopolymer films. Among the investigated biopolymers, chitosan can be considered very promising for the fabrication of durable films.

Funding Open access funding provided by Università degli Studi di Palermo within the CRUI-CARE Agreement. The work was 
financially supported by the University of Palermo and "Sicilia Eco Tecnologie Innovative" (SETI) PO FESR2014/2020 project (cod. 2017-NAZ-0204).

\section{Declarations}

Conflict of interests The authors declare no competing interests.

Open Access This article is licensed under a Creative Commons Attribution 4.0 International License, which permits use, sharing, adaptation, distribution and reproduction in any medium or format, as long as you give appropriate credit to the original author(s) and the source, provide a link to the Creative Commons licence, and indicate if changes were made. The images or other third party material in this article are included in the article's Creative Commons licence, unless indicated otherwise in a credit line to the material. If material is not included in the article's Creative Commons licence and your intended use is not permitted by statutory regulation or exceeds the permitted use, you will need to obtain permission directly from the copyright holder. To view a copy of this licence, visit http://creativecommons.org/licenses/by/4.0/.

\section{References}

1. B. Joseph, S. Krishnan, V.K. Sagarika, A. Tharayil, N. Kalarikkal, S. Thomas, Emergent Mater. 3, 711 (2020)

2. Z. Yu, Y. Ji, V. Bourg, M. Bilgen, J.C. Meredith, Emergent Mater. 3, 919 (2020)

3. G. Gorrasi, V. Bugatti, G. Viscusi, V. Vittoria, Colloid Polym. Sci. 299, 429 (2021)

4. G. Viscusi, V. Bugatti, G. Gorrasi, Packag. Technol. Sci. 34, 353 (2021)

5. M. Barman, S. Mahmood, R. Augustine, A. Hasan, S. Thomas, K. Ghosal, Int. J. Biol. Macromol. 162, 1849 (2020)

6. A.S. Theus, M.L. Tomov, A. Cetnar, B. Lima, J. Nish, K. McCoy, M. Mahmoudi, V. Serpooshan, Emergent Mater 2, 193 (2019)

7. A. Stavitskaya, S. Batasheva, V. Vinokurov, G. Fakhrullina, V. Sangarov, Y. Lvov, and R. Fakhrullin, Nanomaterials 9, (2019)

8. E.P. Rebitski, M. Darder, C.I. Sainz-Diaz, R. Carraro, P. Aranda, E. Ruiz-Hitzky, Appl Clay Sci 186, 105418 (2020)

9. T. Mohan, C. J. Chirayil, C. Nagaraj, M. Bračič, T. A. Steindorfer, I. Krupa, M. A. A. A. Maadeed, R. Kargl, S. Thomas, and K. Stana Kleinschek, Polymers 13, (2021)

10. M. Liu, R. Fakhrullin, A. Novikov, A. Panchal, Y. Lvov, Macromol. Biosci. 19, 1800419 (2019)

11. E.A. Naumenko, I.D. Guryanov, R. Yendluri, Y.M. Lvov, R.F. Fakhrullin, Nanoscale 8, 7257 (2016)

12. P. Dramou, M. Fizir, A. Taleb, A. Itatahine, N.S. Dahiru, Y.A. Mehdi, L. Wei, J. Zhang, H. He, Carbohydr Polym 197, 117 (2018)

13. K. Govindasamy, N.A. Dahlan, P. Janarthanan, K.L. Goh, S.-P. Chai, P. Pasbakhsh, Appl Clay Sci 190, 105601 (2020)

14. V. Bertolino, G. Cavallaro, S. Milioto, G. Lazzara, Carbohydr Polym 245, 116502 (2020)

15. L. Lisuzzo, G. Cavallaro, S. Milioto, G. Lazzara, Appl Clay Sci 185, $105416(2020)$

16. G. Gorrasi, C. Milone, E. Piperopoulos, M. Lanza, A. Sorrentino, Appl Clay Sci 71, 49 (2013)

17. X. Yang, Y. Zhang, D. Zheng, J. Yue, M. Liu, Appl Clay Sci 190, 105565 (2020)

18. G.P. Udayakumar, S. Muthusamy, B. Selvaganesh, N. Sivarajasekar, K. Rambabu, F. Banat, S. Sivamani, N. Sivakumar, A. Hosseini-Bandegharaei, P.L. Show, J Environ Chem Eng 9, $105322(2021)$
19. V. Bertolino, G. Cavallaro, G. Lazzara, M. Merli, S. Milioto, F. Parisi, L. Sciascia, Ind. Eng. Chem. Res. 55, 7373 (2016)

20. S. Leitner, S. Grijalvo, C. Solans, R. Eritja, M.J. García-Celma, G. Calderó, Carbohydr Polym 229, 115451 (2020)

21. J. Rohowsky, K. Heise, S. Fischer, K. Hettrich, Carbohydr. Polym. 142, 56 (2016)

22. D. E. Ciolacu, R. Nicu, and F. Ciolacu, Materials 13, (2020)

23. H.C. Arca, L.I. Mosquera-Giraldo, V. Bi, D. Xu, L.S. Taylor, K.J. Edgar, Biomacromolecules 19, 2351 (2018)

24. M.-J. Akhtar, M. Aïder, J Packag Technol Res 2, 169 (2018)

25. S.M.F. Kabir, P.P. Sikdar, B. Haque, M.A.R. Bhuiyan, A. Ali, M.N. Islam, Prog Biomater 7, 153 (2018)

26. L. Lisuzzo, M.R. Caruso, G. Cavallaro, S. Milioto, G. Lazzara, Ind Eng Chem Res 60, 1656 (2021)

27. A.C. Hernández-González, L. Téllez-Jurado, L.M. RodríguezLorenzo, Carbohydr Polym 229, 115514 (2020)

28. M.A. Taemeh, A. Shiravandi, M.A. Korayem, H. Daemi, Carbohydr Polym 228, 115419 (2020)

29. M. Farokhi, F. Jonidi Shariatzadeh, A. Solouk, and H. Mirzadeh, Int. J. Polym. Mater. Polym. Biomater. 69, 230 (2020)

30. D. Ma, Y. Jiang, S. Ahmed, W. Qin, Y. Liu, Int J Biol Macromol 141, 378 (2019)

31. K. B. Mukhtar Ahmed, M. M. A. Khan, H. Siddiqui, and A. Jahan, Carbohydr. Polym. 227, 115331 (2020)

32. G. Cavallaro, S. Micciulla, L. Chiappisi, G. Lazzara, J Mater Chem B 9, 594 (2021)

33. C. Huang, G. Fang, Y. Zhao, S. Bhagia, X. Meng, Q. Yong, and A. J. Ragauskas, Carbohydr. Polym. 222, 115036 (2019).

34. L. Lisuzzo, G. Cavallaro, S. Milioto, G. Lazzara, New J Chem 43, 10887 (2019)

35. V. Bertolino, G. Cavallaro, G. Lazzara, S. Milioto, F. Parisi, New J Chem 42, 8384 (2018)

36. I. Blanco, Materials 11, 1383 (2018)

37. I. Blanco, L. Abate, M.L. Antonelli, F.A. Bottino, Polym Degrad Stab 98, 2291 (2013)

38. M. Tomassetti, A. Catalani, V. Rossi, S. Vecchio, J Pharm Biomed Anal 37, 949 (2005)

39. M.M. Calvino, L. Lisuzzo, G. Cavallaro, G. Lazzara, S. Milioto, Thermochim Acta 700, 178940 (2021)

40. S.-W. Yen, W.-H. Chen, J.-S. Chang, C.-F. Eng, S. Raza Naqvi, and P. L. Show, Sustainability 13, (2021).

41. B. Fidalgo, M. Chilmeran, T. Somorin, A. Sowale, A. Kolios, A. Parker, L. Williams, M. Collins, E.J. McAdam, S. Tyrrel, Renew Energy 132, 1177 (2019)

42. Y.-H. Hao, Z. Huang, Q.-Q. Ye, J.-W. Wang, X.-Y. Yang, X.-Y. Fan, Y.-L. Li, Y.-W. Peng, J Therm Anal Calorim 128, 1077 (2017)

43. P. Paik, K.K. Kar, Mater Chem Phys 113, 953 (2009)

44. P. Paik, K.K. Kar, Polym Degrad Stab 93, 24 (2008)

45. P. Paik, K.K. Kar, Surf Eng 24, 341 (2008)

46. S. Vyazovkin, A.K. Burnham, J.M. Criado, L.A. Pérez-Maqueda, C. Popescu, N. Sbirrazzuoli, Thermochim Acta 520, 1 (2011)

47. M.J. Starink, Thermochim Acta 404, 163 (2003)

48. I. Blanco, L. Abate, F.A. Bottino, Thermochim Acta 655, 117 (2017)

49. M. Erceg, I. Krešić, M. Jakić, B. Andričić, J Therm Anal Calorim 127, 789 (2017)

50. M. Catauro, A. Dell'Era, S.V. Ciprioti, Thermochim Acta 625, 20 (2016)

51. M. Brusnikina, O. Silyukov, M. Chislov, T. Volkova, A. Proshin, I. Terekhova, J Therm Anal Calorim 127, 1815 (2017)

52. I. Kritskiy, T. Volkova, A. Surov, I. Terekhova, Carbohydr Polym 216, 224 (2019)

53. D. Jelić, T. Liavitskaya, S. Vyazovkin, Thermochim Acta 676, 172 (2019) 
54. Y. Liu, C.-J. Zhang, J.-C. Zhao, Y. Guo, P. Zhu, D.-Y. Wang, Carbohydr Polym 139, 106 (2016)

55. B. M. Liebeck, N. Hidalgo, G. Roth, C. Popescu, and A. Böker, Polymers 9, (2017)

56. M. Jakić, N.S. Vrandečić, M. Erceg, J Therm Anal Calorim 127, 663 (2017)

57. M. Jakić, N. Stipanelov Vrandečić, and M. Erceg, Eur. Polym. J. 81, 376 (2016)

58. G. Cavallaro, A. Agliolo Gallitto, L. Lisuzzo, and G. Lazzara, Cellulose 26, 8853 (2019)
59. A. Chamas, H. Moon, J. Zheng, Y. Qiu, T. Tabassum, J.H. Jang, M. Abu-Omar, S.L. Scott, S. Suh, A.C.S. Sustain, Chem. Eng. 8, 3494 (2020)

Publisher's note Springer Nature remains neutral with regard to jurisdictional claims in published maps and institutional affiliations. 